Vol. I No. 3 - December 2020

\title{
Implementation of Build Back Better (BBB) Framework in Achieving Sustainable Development Goals
}

\section{Case Study: Housing Reconstruction at Duyu Urban Village, Palu City, Central Sulawesi Province}

\author{
Ayu Erlinna ${ }^{1}$, Djoko Santoso Abi Suroso ${ }^{2}$, and Kim Dowon ${ }^{3}$ \\ Directorate General of Housing, Ministry of Public Works and Housing (PUPR), Jakarta, Indonesia ${ }^{1}$ \\ Master of Urban and Regional Planning, Institut Teknologi Bandung, West Java, Indonesia ${ }^{2}$ \\ Graduate School of Science and Engineering (GSSE), Ritsumeikan University, Shiga, Japan ${ }^{3}$ \\ ayuerlinna22@gmail.com;dsuroso@pl.itb.ac.id; kim21@fc.ritsumei.ac.jp
}

\begin{abstract}
The occurrence of 7.5M earthquake and tsunami in Central Sulawesi in September 2018 resulted in 2,045 fatalities and 67,310 damaged houses. In line with RIPB and SDGSs 11, the government has established a masterplan for rehabilitation and reconstruction of Central Sulawesi by adopting the build back better concept. This research tries to analyze the implementation of BBB framework which focuses on reducing the risk of housing reconstruction in Duyu urban village, using the scale and index method. The result shows that the implementation of risk reduction falls into a moderate level although some indicators are still in the poor category. In accordance with SDGs, at least four key factors related to disaster mitigation, specifically SDGs 11 - making cities and human settlements inclusive, safe, resilient and sustainable - have been successfully achieved, which are: $11.5 ; 11 . b 1 ; 11 . b 2 ;$ and 11.c1. This result indicates that the Duyu housing reconstruction has gone through analysis and consideration of risk reduction practices involving five variables by adopting the BBB framework in creating community resilience while achieving SDGs in Indonesia.
\end{abstract}

Keywords: Build Back Better, Disaster Risk Reduction, Housing Reconstruction

ARTICLE INFO

Received: Oct 24, 2020

Received in revised form: Oct 29, 2020

Accepted: Oct 30, 2020
JISDeP - The Journal of Indonesia Sustainable Development Planning Published by Centre for Planners'

Development, Education, and Training (Pusbindiklatren),

Ministry of National Development Planning/ National Development

Planning Agency (Bappenas), Republic of Indonesia
Address: Jalan Proklamasi 70

Central Jakarta, Indonesia 10320

Phone: +62 $2131928280 / 3192828$

Fax: +62 2131928281

E-mail: pusbindiklatren@bappenas.go.id

Supported by Indonesian Development Planners Association (PPPI) 


\section{Introduction}

The realization of the emergence of the resilient recovery concept has given rise to a concept now commonly referred to as "Build Back Better" (BBB). The phrase of BBB actually became popular during the large-scale reconstruction effort following the Indian Ocean Tsunami disaster in 2004 (Clinton, 2006). Since then, this phrase has become more officially embraced with the creation of sets of BBB Guidelines by Clinton in 2006 to steer recovery activities towards achieving resilient goals. This concept is proposed as a complete recovery framework that integrates numerous elements to create a resilient community in the future (Kennedy, Ashmore, Babister, \& Kelman, 2008).

Several attempts to adapt this framework into disaster risk management have been made in many countries, such as in 2011 by the Victorian Bushfire Reconstruction and Recovery Authority, Australia that created a Recovery and Reconstruction Framework that focused on the safety and well-being of communities. However, the adaptation of this framework had shortfalls due to complications of the post disaster environment (Mannakkara \& Wilkinson, 2013b, 2013a). After being created, improvements to the BBB framework were carried out to complete this concept so that it can be effectively implemented. One previous study conducted by Mannakara using two case studies of Sri Lanka and the case in Australia produced a framework solution to allow the BBB concept to be adopted (Mannakkara, 2014).

Indonesia, as a member of the Sendai Framework Risk Reduction is obliged to implement and develop the BBB framework as post Disaster Risk Management (United Nations, 2016). In accordance with the Indonesia Sustainable Development Goals roadmap 2030, specifically Goal 11, creating Sustainable Cities and Communities, the government of Indonesia is integrating this concept into the Disaster Prevention Masterplan (Rencana Induk Penanggulangan Bencana 2015-2045) with the following mission: Indonesia is Resilient to Disaster to Support the Sustainable Development Goals (BNPB, 2018). As a result, the National Disaster Management Agency (BNPB) adapted the BBB framework by creating the concept of Build Back Better, Safer and more Resilient to be implemented in disaster areas (BNPB, 2015).

As previously explained, the challenge in implementing this framework is the absence of detailed guidelines for applying and measuring this framework into action, thus making it difficult for Indonesia to apply and evaluate the performance of the BBB framework (Mannakkara \& Wilkinson, 2014). Another problem related to risk reduction as part of this framework is that many countries including Indonesia still do not have multi-hazard assessment for disaster risk reduction (DRR) as reconstruction is susceptible to other hazards (GFDRR, 2010). Meanwhile, DRR is an essential aspect in implementing the BBB framework because through integrated DRR it can minimize the number of casualties and extensive damage of infrastructure so as to create a city that is resilient to disasters as one of the key factors addressed in the SDGs. Based on the existing problems, this study has an objective to determine the implementation of the BBB framework by the government in achieving the SDGs, with a case study of housing reconstruction process in the Palu disaster area.

\section{Methodology}

\subsection{Theoretical Framework}

This research departs from the concept of Disaster Risk Management (DRM) as a global standard effort to address the four phases of the disaster approach, namely mitigation, preparedness, response, and recovery activities (Carter, 2008). Since the recovery phase is highly crucial for victims after a disaster, this has led to the realization of the emergence of a resilient recovery concept. One concept adapted by the global world is called "Build Back Better" which is defined as rebuilding community, the environment and infrastructures better than before in order to reduce existing vulnerabilities (GFDRR, 2018).

One of the current discoveries was made by Sandeeka Mannakara in 2014 using two environmental case studies 1) Sri Lanka (2004 Indian Ocean Tsunami disaster recovery); and 2) Australia (2009 Victorian Bushfire recovery) producing a framework solution that allows the BBB to be adopted in post-disaster situations efficiently and effectively (Mannakkara, 2014). This framework consists of three main categories, namely: 1) Risk Reduction; 2) Community Recovery; and 3) Implementation, each of which has two principles (Mannakkara \& Wilkinson, 2014). Specifically on the aspect of Risk Reduction, it is stated that risk reduction is primarily achieved through the implementation of two principles, which are: Principle 1) Improvement of Structural Design, depicting improving structural designs and enforcing them through revised building codes; and Principle 2) Land-use Planning, representing the use of hazard and risk-based land-use plans to minimize risks (Mannakkara, 2014). 
Based on previous studies related to the BBB framework conducted by Manakkara, this framework depicts a holistic recovery effort including key multivariate actors, such as state and local governments, private sectors, communities, NGOs, and others. Nevertheless, the government has a big role in the first category, risk reduction, because this category has implications for policies and regulations in its implementation. Following that reason, my research points out a risk reduction category which involves six variables 1) DRM Capacity; 2) Building Codes and Regulations; 3) Cost and Time; 4) Quality; 5) Risk-based Zones; and 6) Resettlement.

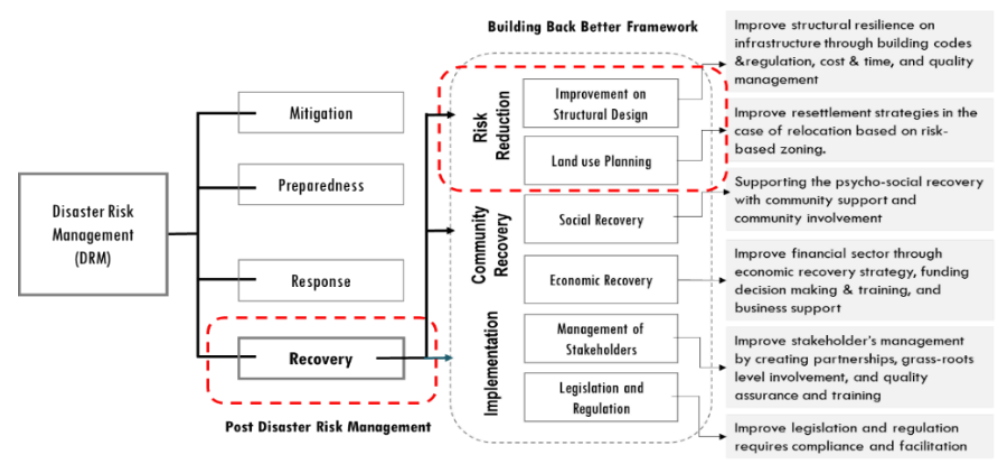

Figure 1. Theoretical Framework of the Study Source: (Author Analysis, 2019)

\subsection{Data Collection}

This research uses two types of data which are primary data and secondary data. The primary data were collected using questionnaires to the survey target (purposive sampling) while secondary data were obtained from government institutions. Respondents were categorized into three domain targets, namely the central government, regional governments, and an expert team comprised of 19 respondents from 10 institutions. Meanwhile the questionnaires consisted of three sections 1) capacity of disaster risk management; 2) housing reconstruction process; and 3) constraints and challenges in the reconstruction process with a total of 45 questions to be answered. It was conducted by using face to face interviews with respondents in February 2020. The field survey was carried out in several locations of Palu postdisaster areas: 1) The liquefaction areas in Petobo, Jono Oge, and Sidera; 2) The tsunami area near the beach; 3) The housing reconstruction area in Tondo-Talise; and 4) various points of temporary housing.

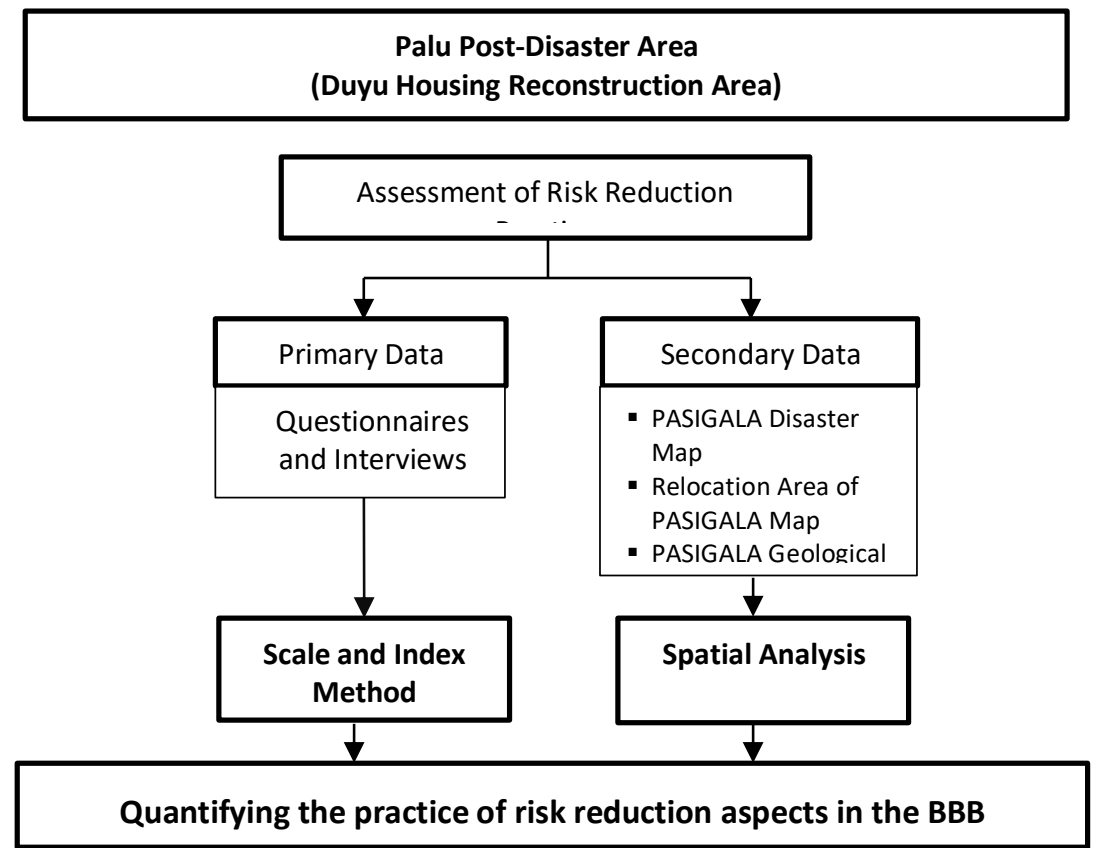

Figure 2. Methodology Diagram of the Study Source: (Author Analysis, 2020) 


\subsection{Analytical Method}

\subsubsection{Scale and Index Method}

Measurement is a crucial part of the research and so are the evaluation efforts in quantifying the results. This study uses a scale and index method in order to capture the degree of indicators executed through ordinal level measurements. To be more specific, it uses the Likert scale, a scale that measures underlying phenomenon by aggregating an individual's rating of his/her perception using ordinal-level categories that are ranked along a continu.

Table 1: Suggested Data Analysis Procedures for Likert-Type and Likert Scale Data

\begin{tabular}{|l|l|l|}
\hline & \multicolumn{1}{|c|}{ Likert-Type Data } & \multicolumn{1}{c|}{ Likert Scale Data } \\
\hline Central Tendency & Median or mode & Mean \\
\hline Variability & Frequencies & Standard deviation \\
\hline Associations & Kendall tau B or C & Pearson's r \\
\hline Other Statistics & Chi-square & ANOVA, t-test, regression \\
\hline
\end{tabular}

\subsubsection{Spatial Analysis}

Spatial analysis is a diverse and comprehensive process that includes simple visual analysis of maps and imagery, computational analysis and geographic patterns, and other advanced predictive modeling (ESRI, 2013). One method generally used is overlay analysis through Geographic Information System (GIS) where the operation is merely a stack of map layers that is able to express causal relationships where temporal sequences also an integral part (Ahlqvist, 2019). ESRI describes that in general there are two methods for performing analysis; the first is a feature overlay (overlaying points, lines, or polygons) and the other is a raster overlay. This research uses a raster overlay in which each layer references the same geographic location then combines the characteristics of numerous layers into a single layer.

\section{Study Area Overview}

\subsection{Chronology of the Latest Disaster Event in Palu}

Friday, 28 September 2018 was a nightmare for Palu; a 7.5 magnitude shallow strike-slip earthquake occurred in Central Sulawesi with an epicenter of $0.18^{\circ} \mathrm{S} ; 119.85$ that generated a significant tsunami from Palu bay around fifteen minutes after the quake (Paulik \& Gusman, 2019). Seven major earthquakes with a magnitude of between 7.5 and 5.7 hit the island of Sulawesi within 7 hours and within $100 \mathrm{~km}$ resulting in the three worst-hit areas of Donggala, Palu, and Sigi (European Commission, 2018). This catastrophic disaster scenario when a large earthquake triggered tsunamis, liquefaction, and landslides causing direct damage which was reported by BNPB had 2,045 fatalities, 20,679 injuries, and 67,310 houses damaged where Palu was the most affected area among other cities/regencies as listed in Table 2 (AHA Centre, 2018). Table 2 shows that more than 65,000 houses in Palu city were damaged, while in contrast in Donggala only 680 houses and in Sigi 897 houses were damaged.

Table 2: Human Casualties and Damage by City/ Regency

\begin{tabular}{lcccc}
\hline $\begin{array}{c}\text { Human Casualties } \\
\text { and Damage }\end{array}$ & Palu city & $\begin{array}{c}\text { Donggala } \\
\text { regency }\end{array}$ & Sigi regency & $\begin{array}{c}\text { Parigi Moutong } \\
\text { regency }\end{array}$ \\
\hline Fatalities & $\mathbf{1 , 6 3 6}$ & 171 & 222 & 15 \\
Injuries & $\mathbf{3 8 , 6 2 1}$ & Severe: 2,$549 ;$ Light: 8,130 & t.b.a \\
IDPs & 20,223 & 15,600 & t.b.a \\
Damaged houses & $\mathbf{6 5 , 7 3 3}$ & 680 & 897 & \\
\hline
\end{tabular}




\subsection{Alternative Areas for Housing Reconstruction}

Palu, as the most affected city in Central Sulawesi, adopted the build back better concept to restore its damaged areas which cover five main sectors: housing, infrastructure, social, economy, and cross sectoral. Focusing on housing reconstruction, the government gives options for victims to live, either relocating to a new settlement area (ex situ) or repairing their damaged houses in the initial area (in situ) as long as they are not located in a restricted area (ZRB 4). For the ex situ concept, four villages were proposed as alternative areas for new settlements for victims of 1) Duyu; 2) Tondo Talise; 3) Pombewe; and 4) Petobo (Bappeda Kota Palu, 2019).

Currently, housing reconstruction projects have been conducted in three areas, Duyu, Tondo Talise, and Pombewe with various sources of budget (ministries, local governments, private sector, and organizations). The Ministry of Public Works and Public Housing, which is responsible for housing provision, is at the present time actively participating in the construction of 450 houses in Duyu and 500 units in Pombewe. However, when we were conducting this research, Pombewe village was still in the auction phase. Therefore, based on this reason, this research will focus on the housing reconstruction process carried out in Duyu urban village by the Ministry of MPWH. Duyu as an alternative area for relocation covering an area of $79.3 \mathrm{Ha}$ has a building right certificate from the government. Referring to Palu Spatial Plan year 2010-2030, Duyu is designated as a low-density residential area, disaster evacuation area and low activity region. However, based on research by the Geology Agency, Duyu, which is located in ZRB 3,implies that the development in this area should take into consideration the Palu-Koro Fault near this area (Bappeda Kota Palu, 2019).

\section{Results and Discussions}

This part will discuss the measurement of risk reduction implementation through designated indicators which represent each variable using the scale and index method. The aim is to quantify the implementation of risk reduction practices in the housing reconstruction process. There are 40 indicators in total that cover six variables, and the data analysis used SPSS version 18.0 statistical software as the main tool. The first step taken in analyzing the Likert scale data is measuring the reliability or internal consistency to determine whether the survey is reliable. The Cronbach's Alpha score for all variables is 0.943 indicating the survey test has good internal consistency and questions are correlated with each other, so that further analysis shall carry out.

In the original version, Likert uses five options that include neutral options; however, the response format has been expanded including removing the neutral category. Therefore, this research carried out a rating scale of 1 to 4 in order to prevent respondents from standing in the middle or giving neutral answers with item expressions that may be different from one to another. Then the results ranged from bad to good categories based on the index score with the categorization distribution listed in Table 3. A score of $1.00-1.75$ is in the Bad category, $1.76-2.50$ is in the Poor category, $2.51-3.25$ is in Moderate category, and $3.26-4.00$ is in Good category.

Table 3: Category Distribution based on Index Score

\begin{tabular}{|c|l|}
\hline Index Score & \multicolumn{1}{|c|}{ Category } \\
\hline $1.00-1.75$ & Bad \\
\hline $1.76-2.50$ & Poor \\
\hline $2.51-3.25$ & Moderate \\
\hline $3.26-4.00$ & Good \\
\hline
\end{tabular}

Source: (Author Analysis, 2020) 


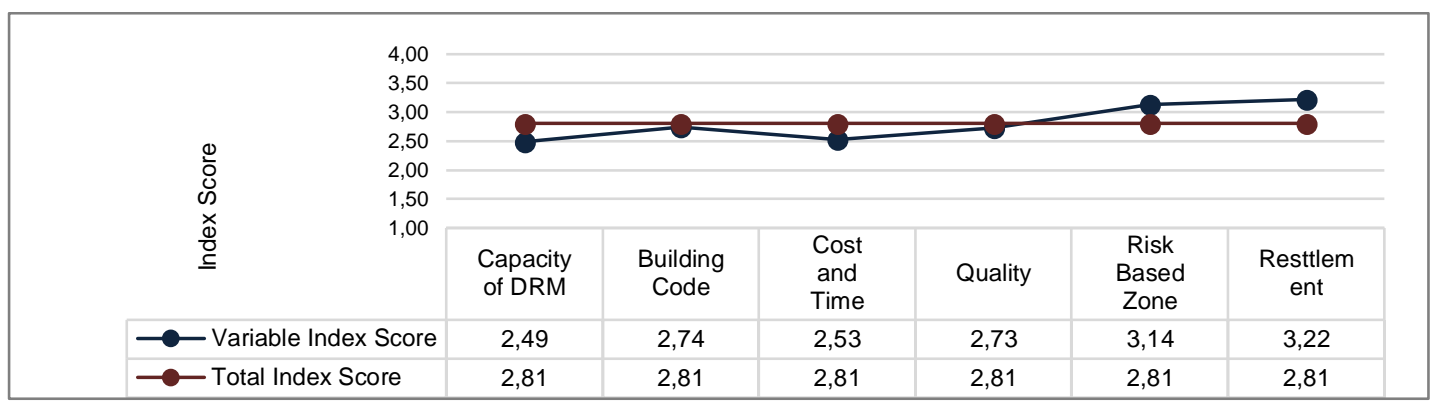

Figure 3. Index Score for Each Variable in Risk Reduction Aspect Source: (Author Analysis, 2020)

The survey found that the housing reconstruction strategy based on disaster risk mitigation proposed by the government (Governor Law No. 10 of 2019 regarding Post Disaster Rehabilitation and Reconstruction Plan) did not reach the maximum score, merely the "moderate" category with a total index score of 2.81 as shown in figure 4 while sequence Resettlement had the highest mean score of 3.22 followed by Risk Based Zone with 3.14, and the rest which are Building Code, Quality, Cost and Time, and DRM Capacity stood at 2.74, 2.73, 2.53, and 2.49, respectively. The detailed results are illustrated in Table 4 by indicating performance score and categories of each variable used in the research.

Table 4: Indicators of Performance Score of Risk Reduction Practices in Duyu Urban Village Housing Reconstruction

\begin{tabular}{|c|c|c|c|c|c|c|}
\hline \multirow{2}{*}{ Code } & \multirow{2}{*}{ Indicator } & \multirow{2}{*}{ Score } & \multicolumn{4}{|c|}{ Category } \\
\hline & & & Bad & Poor & Moderate & Good \\
\hline \multicolumn{2}{|c|}{ (1) DRM Capacity } & 2.49 & & & & \\
\hline 1.1 & Availability of DRM policy/guidelines & 2.63 & & & & \\
\hline 1.2 & Effectiveness of guidelines & 2.79 & & & & \\
\hline 1.3 & Availability of a tsunami warning system & 2.11 & & & & \\
\hline 1.4 & Effectiveness of the tsunami warning system & 2.16 & & & & \\
\hline 1.5 & Availability of disaster evacuation signs & 2.32 & & & & \\
\hline 1.6 & Availability of evacuation drills & 2.37 & & & & \\
\hline 1.7 & Availability of DRM related institutions & 3.05 & & & & \\
\hline \multicolumn{2}{|c|}{ (2) Building Codes and Regulation } & 2.74 & & & & \\
\hline 1.8 & Availability of housing reconstruction guidelines & 2.63 & & & & \\
\hline 1.9 & Compliance of building permit & 2.84 & & & & \\
\hline 1.10 & Compliance of multi hazard assessment for structure design & 2.95 & & & & \\
\hline 1.11 & Consideration of innovative technologies & 2.68 & & & & \\
\hline 1.12 & Compliance of building technical requirements & 2.21 & & & & \\
\hline 1.13 & Consideration of standard requirements for materials & 3.05 & & & & \\
\hline 1.14 & Consideration of bearing capacity & 2.95 & & & & \\
\hline 1.15 & Education of community and stakeholders for risk reduction & 2.58 & & & & \\
\hline \multicolumn{2}{|r|}{ (3) Cost and Time } & 2.53 & & & & \\
\hline 1.16 & Availability of pre-planned strategies & 2.53 & & & & \\
\hline 1.17 & Consideration of manageable $\&$ realistic cost & 3.26 & & & & \\
\hline 1.18 & Utilization of local materials & 2.58 & & & & \\
\hline 1.19 & Utilization of recycled materials & 1.79 & & & & \\
\hline 1.20 & Involvement of community skills and knowledge & 2.47 & & & & \\
\hline 1.21 & Provision of an assistance system in quality control & 2.84 & & & & \\
\hline 1.22 & Promotion of building codes adoption & 2.16 & & & & \\
\hline 1.23 & Preparation of long-term funding & 2.58 & & & & \\
\hline \multicolumn{2}{|c|}{ (4) Quality } & 2.73 & & & & \\
\hline 1.24 & Consideration of environmental and health aspects & 3.32 & & & & \\
\hline 1.25 & Consideration of the number of majority households & 2.37 & & & & \\
\hline 1.26 & Consideration of an expandable housing design & 2.68 & & & & \\
\hline 1.27 & Companion of professional supervision & 3.16 & & & & \\
\hline 1.28 & Availability of regular workshops and training & 2.47 & & & & \\
\hline 1.29 & Application of traditional materials and techniques & 2.37 & & & & \\
\hline \multicolumn{2}{|r|}{ (5) Risk Based Zone } & 3.14 & & & & \\
\hline 1.30 & $\begin{array}{l}\text { Adoption of integrated hazard assessment for disaster-prone } \\
\text { maps }\end{array}$ & 3.00 & & & & \\
\hline 1.31 & Adoption of multi-hazard assessment to establish a master plan & 3.37 & & & & \\
\hline 1.32 & Consideration of coastal buffer zone & 3.05 & & & & \\
\hline
\end{tabular}




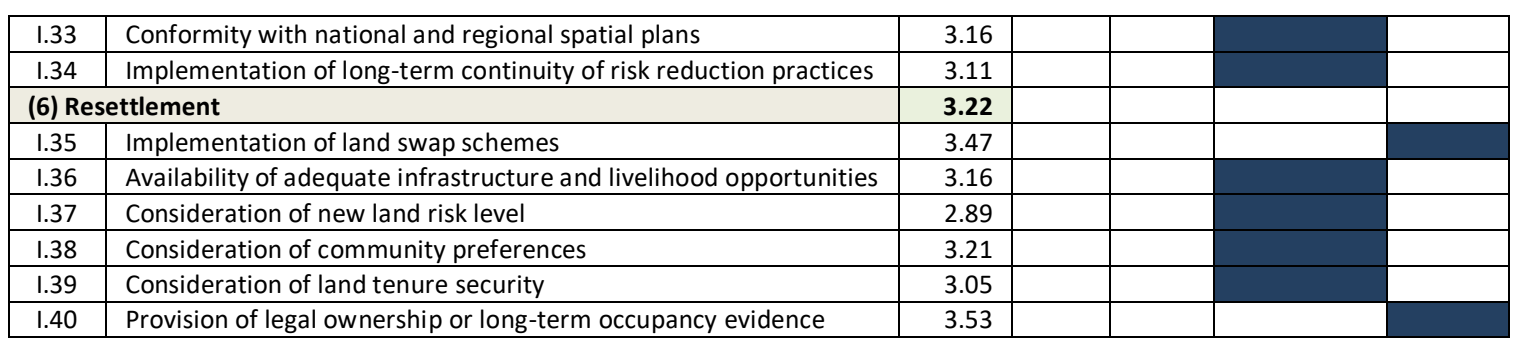

Source: Author analysis, 2020

\subsection{Disaster Risk Management Capacity}

In Indonesia, BNPB is the primary agency at the national level responsible for disaster risk management from mitigation, preparedness, response, and recovery efforts. Under the umbrella of BNPB, they have the right to lead coordinating body in disaster response and also to mobilize the equipment in disaster response. BNPB has a vertical institution at the provincial and local levels, the Regional Disaster Management Agency (BPBD), which has a role as the executor of DRM in provinces/regions with guidance from the headquarters. Central Sulawesi and Palu have regional level BPBDs which are responsible for handling disaster mitigation and recovery after the PASIGALA earthquake. Besides BNPB, another essential institution in Indonesia to support DRM is the Agency for Meteorology, Climatology and Geophysics (BMKG) which disseminates the Indonesia Tsunami Early Warning System (InaTEWS) established in 2005 and started officially in 2008 (Center for Excellence in Disaster Management \& Humanitarian Assistance, 2018).

This variable addresses the current situation (pre disaster event) of DRM in Palu city, Central Sulawesi province which consists of seven indicators concerning the policy, institution, and disaster infrastructure aspect at the location. Figure 4 illustrates the performance of each indicator in comparison to the overall index score of this variable of 2.49 , which falls into "poor" category. This current situation implies that the readiness of the government for disaster resilience needs to be improved to reduce future vulnerability.

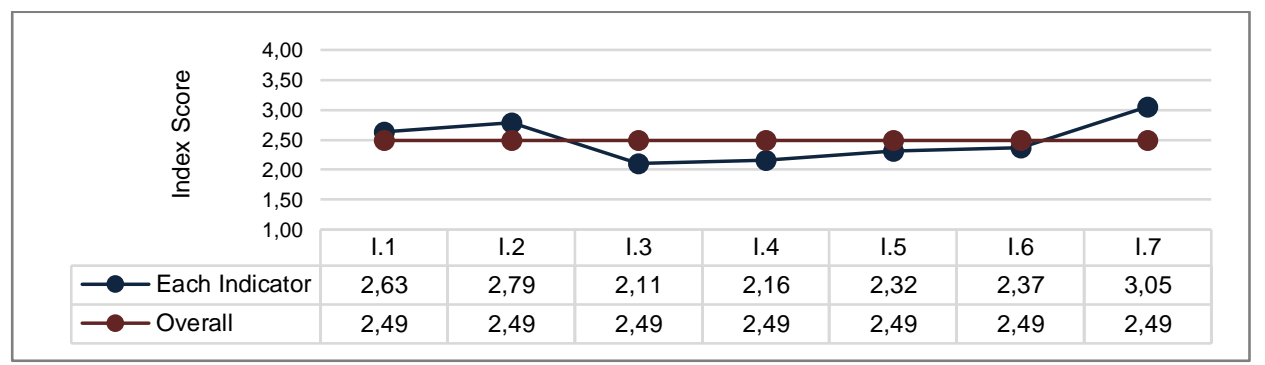

Figure 4. Index Score Performance for DRM Capacity Variable Source: (Author Analysis, 2020)

As described in Figure 4, there are four indicators that have "poor" performance scores, namely I.3, I.4, I.5 and 1.6. These four indicators are related to the tsunami warning system and disaster evacuation. As for disaster infrastructure in Palu, the government has provided a tsunami early warning system (InaTEWS) developed by BMKG. However, this system is not only damaged and in poor condition but there have also been reports of vandalism of supporting equipment with several buoys being damaged, missing or stolen, and dead due to lack of maintenance. Therefore, the system is not functioning properly in notifying the public regarding the latest tsunami event. As a result, the performance indicators 1.3 and I.4 regarding the availability and effectiveness of tsunami early system have the lowest index scores namely only 2.11 and 2.16.

Slightly higher than the tsunami early warning system, the availability of adequate signs or information regarding disaster evacuation routes and assembly points has a performance score of 2.32 while the availability of an evacuation drill only has a score of 2.37. The signs are visible in certain areas near the seashore, but in residential areas the signs are not noticeable. The limited number of signs causes confusion in the community when a disaster occurs and it can lead to the loss of life because they do not understand where to go to reach a safer area. This condition prompted local governments to be 
more aware of the availability of disaster warning signs for the community, and after the Palu tsunami they repaired and improved these signs.

In addition to the availability of disaster warning signs, the presence of evacuation drills or simulation exercise for the community regarding how to deal with disasters are also crucial to do to increase public awareness and knowledge about how to respond to emergency situations. Since the earthquake and tsunami in September 2018, the government of Palu has committed to strengthening public resilience through workshops and evacuation drills as part of the disaster-resilient city program. This policy is in accordance with the achievement of SDGs goal 11, specifically in clause 11.b.1, the implementation of mitigation and adaptation plans and policies and 11.b.2 countries with existing local disaster reduction strategy.

\subsection{Building Codes and Regulations}

In general, the housing reconstruction process in Palu post disaster area refers to Law of Republic of Indonesia No. 28 of 2002 regarding Buildings while the detailed guidelines refer to the Regulation of the Ministry of Public Works and Housing No. 5 of 2016 regarding Building Construction Permits, especially Appendix II on the specifications of earthquake resilient and prototype design for one-story building. In principle, the main concept in housing reconstruction is to use the knock down method (RISHA) which is proposed as a practical and safe house for post-disaster recovery (Ministry of Public Works and Housing, 2015). There are eight indicators involved in this variable to determine the performance of building codes and regulations in the post-disaster area of Palu. The overall achievement of a performance index of 2.74 that represents the execution of this variable reaches the moderate category. The majority of indicators are categorized into moderate level, even though there is one indicator that falls under poor performance, compliance with building codes.

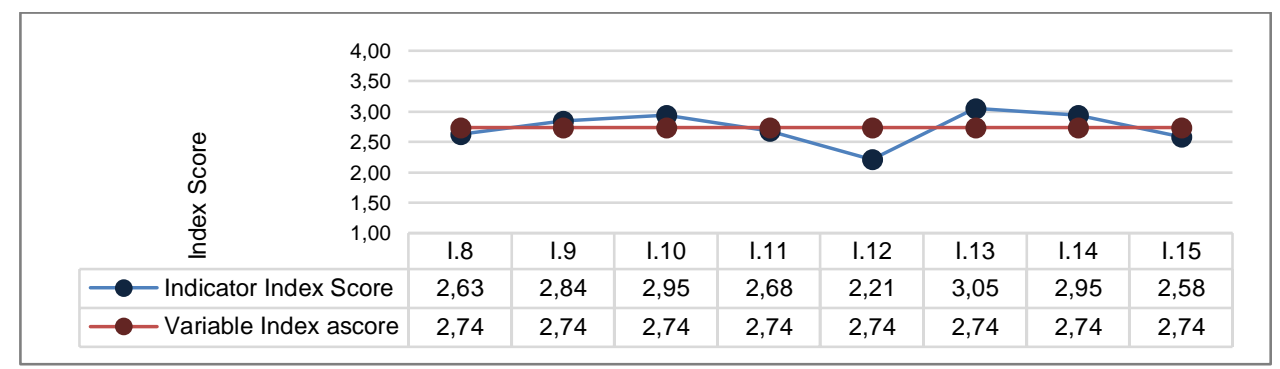

Figure 5. Index Score for Building Performance Codes \& Regulations Variables Source: (Author Analysis, 2020)

Referring to Figure 6, the performance index for building codes and regulations, it can be seen that the government has integrated the majority of variables from this aspect with BBB practice. This situation implies a strategy and policy for the reconstruction process considering the design parameters to determine whether to just require restoration for damaged houses or to rebuild new ones by considering the compliance of the multi hazard assessment to risk reduction for the structural design. Besides, the government should also adopt innovative technologies and local wisdom for housing design using RISHA as the prototype design for permanent housing in the post-disaster area of Palu with SDGs key factor number 11.c.1, sustainable and resilient buildings. This concept was developed by the MPWH in order to accommodate the needs of low-middle income housing as well as emergency housing by adopting knockdown technology which is appropriate for local conditions and saves time.

On the other hand, there is one indicator in this variable (I.12) which has "poor" performance with a score of 2.21, which is compliance with building technical requirements (fire hydrants, disabled facilities, earthquake alarms, evacuation routes, and assembly points) in new housing areas. Unfortunately, the public facilities as listed in the technical design for housing reconstruction in Palu do not include disaster mitigation appliances as a preparation for future hazard. This situation portrays that the disaster mitigation aspect is still not a priority in development planning although it could be a good start to raise the awareness of public by creating a supportive environment. 


\subsection{Cost and Time}

According to the estimation of BNPB, the costs for the rehabilitation and reconstruction project by adopting Build Back Better and Safer are up to Rp. 22.8 trillion including the needs for reconstruction of victims' housing. Palu as the city with the worst damage has the highest budget for rehabilitation and reconstruction compared to Sigi and Donggala with Rp. 18.931 trillion. The budget needed for each sector in Palu includes settlement, infrastructure, social, economic, and cross sectoral and housing reconstruction of Rp. 4.776 trillion equals to one quarter of the overall rehabilitation budget. The high budget needed for housing reconstruction does not only refer to the application of new housing methods but also refers to the establishment of a map of disaster-prone areas with a multi hazard assessment to determine a proper and safe location. The extra costs are incurred by adopting technologies and materials to improve structural resilience and also enforcing compliances with building codes and spatial plans. Time pressure in the recovery process with expectations for fast results contribute to ignorance towards building codes and hazard assessments which lead to future vulnerabilities for inhabitants. The implementation period of the rehabilitation and reconstruction process in Palu took two years from 2019 to 2020 with an evaluation after reconstruction in 2021. An explanation regarding the performance of the cost and time variables is illustrated in Figure 6, where overall indicators have a score of 2.53 with a "moderate" level, even though 3 indicators have poor scores, which are I.19, I.20, and I. 22.

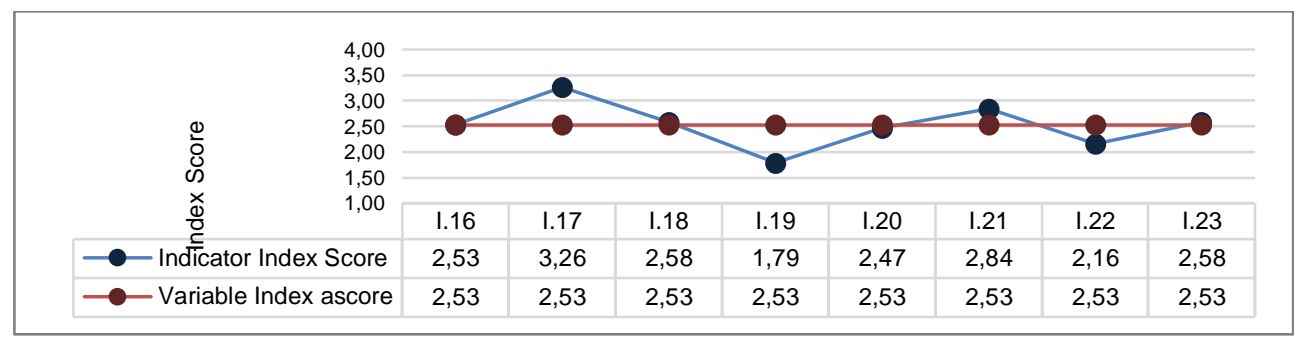

Figure 6. Index Score of Performance for Cost and Time Variables Source: (Author Analysis, 2020)

Basically, the strategy for rehabilitation and reconstruction was planned after the occurrence of the disaster (Master plan of rehabilitation and reconstruction for Central Sulawesi province). This document includes the current condition of Palu and the measures to handle the unpredicted impact (liquefaction case) after the disaster. However, the primary substances in this document had been prepared by the government before the calamity occurred, referring to the RPJMD of Palu. One challenge in conducting housing reconstruction at Duyu is the limitation of local materials in terms of both quantity and quality. Utilization of recycled materials from the damaged houses could be a way to fulfill the needs of local materials and to save some budget from materials. However, because the majority of victim's houses were severely damaged or lost due to liquefaction, then almost none of the wreckage can be used as recycled materials. In addition, the quality of building remains does not meet the standard specifications from the government. This reason explains why I.19 has the lowest score.

Undergoing housing reconstruction in a limited time was not an easy task, as the minimum number of skilled workers to construct RISHA exacerbated the situation. The public and communities volunteered to be involved in the reconstruction process by learning how to build RISHA houses. However, the government still has not maximized the potential of the community, and various workshops and trainings only focus on workers, while the community has no obligation to help. Regarding the promotion of building code practices for housing provision, the government of Palu does not currently have any specific program to support the adoption of building codes and this leads to minimum enforcement of risk reduction practice. Nevertheless, in the future, the World Bank will help in the compliance with building codes for infrastructure under the IDRIP program by investing in disaster-resilient development planning initiatives. This indicates that the government is very serious in achieving the SDGs goal 11, specifically in clause 11.b.1 on the implementation of mitigation and adaptation plans and policies. 


\subsection{Quality}

The quality of design and construction influences the safety aspects of buildings that are determined by good comprehensive planning and the skill level of the workers. Referring to the Palu Action Plan for Rehabilitation and Reconstruction, the recovery strategy is based on a mitigation and risk reduction approach in order to minimize the deprivation for future hazards through the concept of build back better. In the housing reconstruction sector, the government is responsible for providing safe areas for relocation as well as designing new settlement areas that support the social and economic aspects of the victims. Figure 7 provides an overview of the performance indicators on this variable that is categorized into "moderate" performance with an index score of 2.73, although the three indicators I.25, I.28, and I.29 still have "poor" performance.

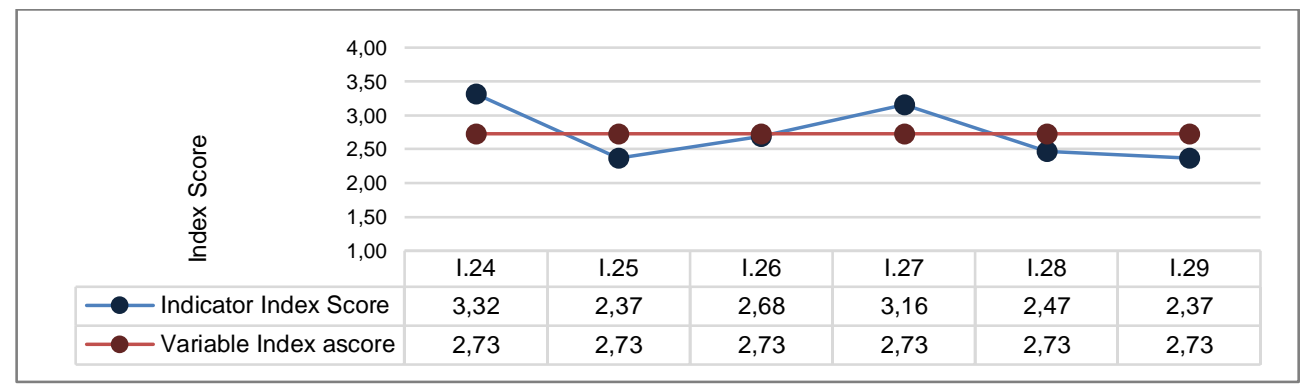

Figure 7. Index Score of Performance for Quality Variable Source: (Author Analysis, 2020)

The RISHA concept proposed for the prototype of housing design meets the PUPR qualifications in the health and safety aspects. The site plan provides green open space and reservoir infrastructure to support the lives of future inhabitants. From Figure 8, regarding the housing reconstruction condition in Palu, it is noticeable that the housing component has recognized the essential standards of housing provision. The buildings have ventilation, clean water channels, drainage systems, distance between houses to reduce the risk of fire, and wide roads that can be accessed by ambulances as well as fire trucks. Meanwhile, the typical unit of one house in this project is $36 \mathrm{~m}^{2}$ with two bed rooms, a dining room, a kitchen as well as a separate toilet/bathroom with the assumption that one household has four family members with a space requirement standard of $9 \mathrm{~m}^{2} /$ person. This design was determined by following the budget availability from the government, so that it does not cover households with more than four family members. Due to this reason, indicator I.25 still has a poor performance.

As explained before, at the present time, the regular workshop and training programs only target housing construction parties to upgrade their skills and are not open for public, so I.28 is categorized into a poor level. For long-term planning, the government prepares a program to increase the risk reduction implementation from the community. On the other hand,, materials as an important aspect of housing should pay attention to local climate and conditions to provide comfort for the occupants. RISHA designs are mainly made of concrete that is durable and suitable for the local climate in Palu. While for the architecture design adopting the typical design of RISHA, no specific traditional techniques are applied in the construction. This explains why I.29 also has poor performance. Nevertheless, several indicators on this variable need to be improved in order to ensure the quality of houses, and the government has tried to achieve the SDGs goal key factor 11.c.1, namely sustainable and resilient buildings.

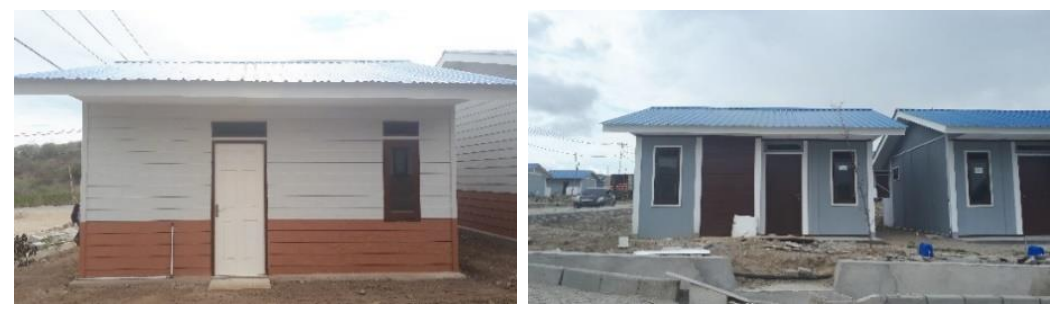




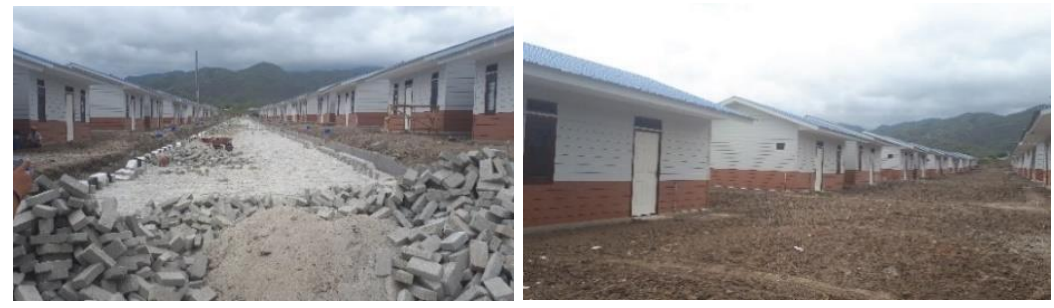

Figure 8. Housing Construction Condition in Palu Source: (Field survey, 2020)

\subsection{Risk-Based Zone}

According to the master plan of the rehabilitation and reconstruction document for Central Sulawesi, the strategy for the structure and spatial plan of the Palu post disaster area is to restore the function or to establish it as a protected area if the location cannot be used anymore. The scope of the new spatial plan covers disaster risk assessment to reduce the hazard vulnerability of future disaster occurrences through the classification of disaster-prone zones (ZRB). ZRB consists of four areas: restricted zone, limited zone, conditional zone, and development zone. For the housing reconstruction process in particular, the government established the LARAP document that contains the principles of resettlement such as relocation facilities, livelihood restoration action plan, institutions, and settlements. The drafting phase of this document involved the community or victims as the permanent occupants to give ideas and recommendations for action plans.

Overall, the alternative areas, including Duyu urban village, have passed the parameter analysis to ensure the safety and legality aspects of the land. Figure 9 illustrates the index score performance of risk-based zone variable and indicators in the Duyu housing reconstruction area. Compared with the previous variables, DRM capacity; building codes and regulations; cost and time; and quality, this variable has a higher score with 3.14 classified as "moderate" achievement. Moreover, the overall indicators in this variable have a score of more than 3.00 that implies that the government took seriously the safety aspect of the new settlement area for victims. This result is in line with the SDGs 11.5 achievement, namely protection of the poor and the vulnerable.

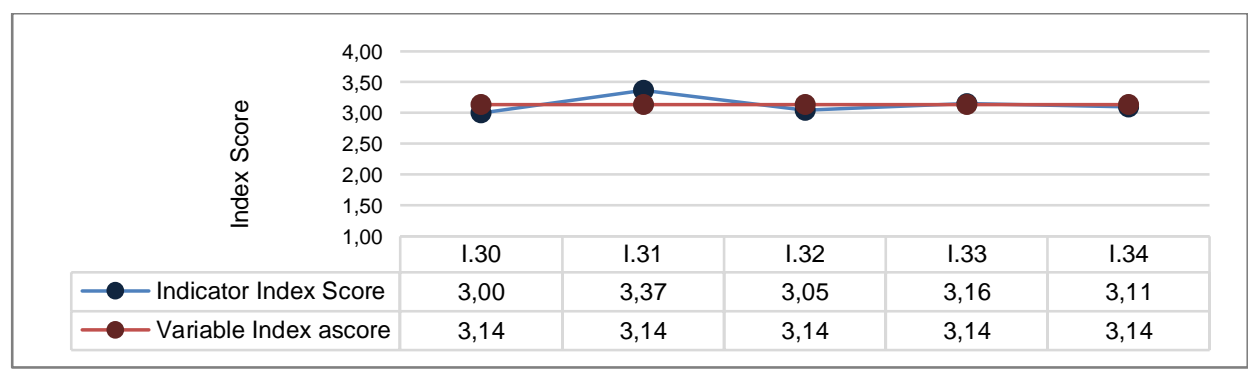

Figure 9. Index Score of Performance for Risk Based Zone Variable Source: (Author Analysis, 2020)

The government through ATR/BPN and other related institutions classifies disaster prone zones into four categories that estimate the potential hazards of a variety of types of disasters (tsunami, earthquake, liquefaction, landslide, and flood). Then in a further step, the data are utilized as the basis for creating a master plan for the rehabilitation and reconstruction of Central Sulawesi. The relocation area in the master plan avoids the red zone in the selection which considers the spatial use for new settlement areas recommended by the government. Moreover, the creation of the master plan for the rehabilitation and reconstruction collaborates with related ministries and institutions and involves the local authority in order to harmonize policies and regulations on spatial planning in Palu city, so that there is compatibility between national and regional planning.

After the completion of the reconstruction process, the challenge faced in Indonesia is how to practice disaster risk reduction in land use in a sustainable manner in the long-term. The government took the initiative that besides giving instructions and restrictions on building development in red zones, they put up warning signs in every red zone in order to make the public stay away from that location and 
prevent them from building houses near the area. However, inadequate law enforcement has caused some residents to disobey the rules and continue to use the space that should not have been built.

\subsection{Resettlement}

Referring to the master plan for the rehabilitation and reconstruction of Central Sulawesi, the resettlement area needs to follow the land compatibility criteria, namely: 1) safe from disasters (active faults, volcanoes, landslides, tsunamis, and floods); 2) located in the cultivation area spatial plan on RTRW (with good carrying capacity); 3) slope < 15\%; 4) the existing land condition has not been constructed; 5) adequate accessibility of water sources and public facilities; and 6) relatively close to the initial area of the victims. The resettlement strategy is aimed for victims whose houses were heavily damaged or lost due to liquefaction by conducting prior public consultation. In general, the resettlement implementation variable for the housing reconstruction process has achieved "moderate" performance as illustrated in Figure 10 with a score of 3.22, which is the highest score among other variables. Based on the figure, the overall indicator of this variable is categorized as "moderate" or "good" performance. This achievement depicts how the government is highly thorough in determining the appropriate strategy and location for victims so they can protect their lives better. Similar to the previous variable, resettlement also contributes to achieving the SDGs key factor 11.5 on protection for the poor and people in vulnerable situations.

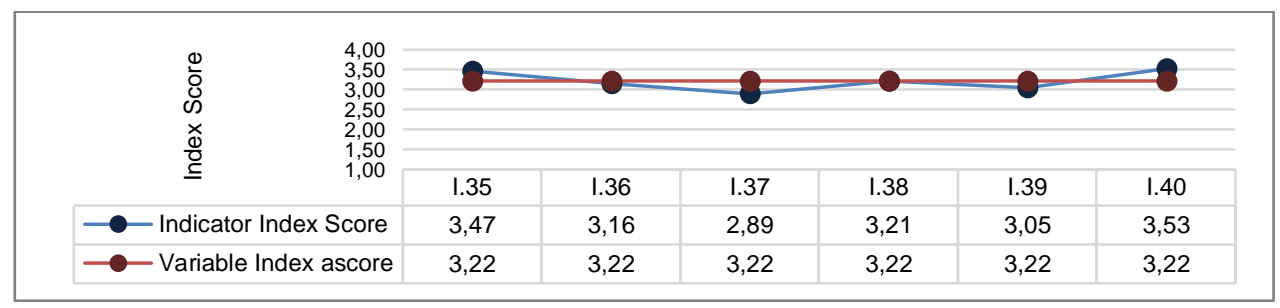

Figure 10. Index Score of Performance for Resettlement Variable Source: (Author Analysis, 2020)

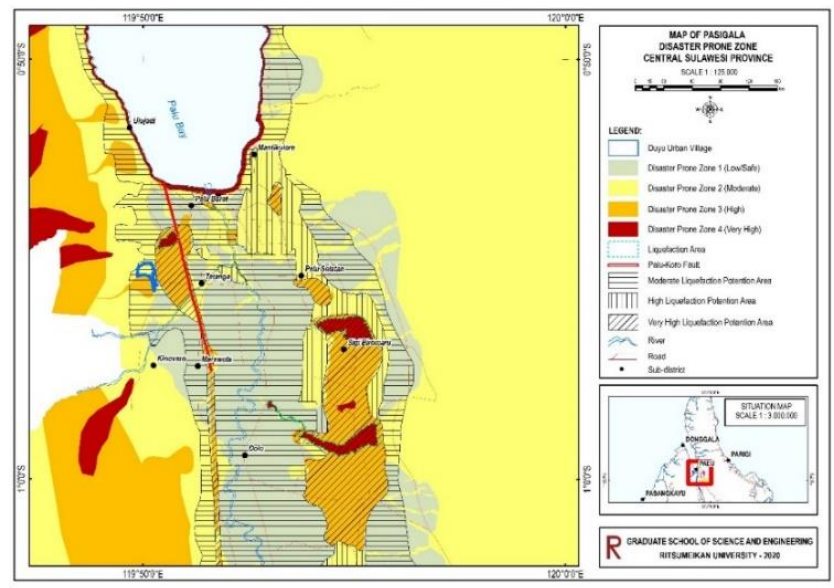

Figure 11. Map of Palu Disaster-Prone Zone

The determination of the relocation area refers to the disaster-prone zone with a multi-hazard assessment by ATR/ BPN and analysis of soil geological condition using the micro zonation method by the Geological Agency. As illustrated in Figure 11, there are four categories of risk levels in the area considering four types of hazards (tsunami, earthquake, landslide, and flood), which are: 1) ZRB 1: Low/Safe level; 2) ZRB 2: Moderate level; 3) ZRB 3: High level; 4) ZRB 4: Very high level with the area scope. It can be seen, that Palu city is mostly located in a safe area in ZRB 1 with the potential for moderate liquefaction and so is Duyu urban village. Even though in RTRW this location is stated to function as a lowdensity settlement, it is geologically located near the Palu-Koro fault, which means this area has a potential hazard to the people who live there. 
Duyu urban village is located 1,361 $\mathrm{m}$ from the nearest river, so that a commercial area (traditional market, culinary zone) will be built in this relocation area to support the victim's livelihood. Fortunately, as stated in the LARAP document, not only the victims affected by the earthquake and liquefaction, but also residents who live in the red zone (ZRB 4) have the right to own a new house in the relocation area or they can apply for subsidies from the government to build new houses on their land as long as the new location is not in the red zone. However, the government prioritizes victims first before local residents and one household can only have one house because this is not a house replacement program.

For the legality aspect of the land in the relocation area, the local government cooperates with ATR/BPN in ensuring land tenure security, so that it is freed from a dispute status. As a consequence, in Duyu urban village the area used for housing reconstruction was reduced from the initial $41.65 \mathrm{Ha}$ (based on the Mayor's decree) to $38.6 \mathrm{Ha}$ (based on the certificate of ATR/ BPN). Meanwhile, regarding the provision of legal ownership for habitants, the government guarantees land ownership for the new house for the victims. However, the land rights for the new house cannot be transferred to other parties within a certain time (in this case 10 years after the certificate is given) and this clause will be written in the certificate. The reason is to prevent the victims from selling off their houses and coming back to the previous area or even using their money for harmful things.

\section{Conclusions}

Based on the findings of the study as previously explained, the implementation of risk reduction as part of the build back better framework for housing reconstruction in Duyu, Palu's post disaster area falls into a moderate level even though some indicators have not properly been implemented. This indicates that the Duyu housing reconstruction process has gone through the analysis and consideration for risk reduction practices that involve five variables (building codes and regulations; cost and time; quality; risk-based zone; and resettlement) by adopting the build back better framework in order to create a resilient community.

To begin with, the current DRM capacity of local authority regarding mitigation and preparedness for disaster is in the poor category with an index score of 2.49. This condition triggered the high level of community vulnerability in facing the earthquake and tsunami in Central Sulawesi in September 2018 as proven by the high mortality rate and damaged buildings after the incident. The current disaster infrastructure and disaster knowledge have failed in preparing the community to encounter emerging situations. Consequently, the government is expected to be able to restore this condition through better measures and practices in order to improve community resilience to face hazards in the future.

Referring to the National Disaster Management plan of 2015-2019, rehabilitation and recovery practices in Central Sulawesi adopt the build back better framework. Specifically, in housing reconstruction, the risk reduction aspect plays a crucial role in ensuring the safety of victims/communities to live their new lives. Based on the results, unfortunately 7 out of 22 indicators of improvement on the structural design aspect have low performance. Nevertheless, at least the four key factors of SDGs 11 making cities and human settlements inclusive, safe, resilient and sustainable - have been achieved by the government. The first key factor 11.5 is Protection of the poor and people in vulnerable situation; the second key factor 11.b.1 is Implementation of mitigation and adaption plans and policies; the third key factor 11.b.2: is Countries with existing local disaster reduction strategy; and the last key factor 11.c.1 is Sustainable and resilient buildings.

This condition concludes that the government of Indonesia has recognized the need for longterm efforts in order to build a community's resilience in facing future hazards towards the recovery process through the implementation of multi hazard assessments in risk reduction practices. Nevertheless, the integration of disaster risk reduction into technical measures is quite weak if it only considers the perspectives of several actors. The active role and awareness of disaster mitigation of various important actors, including ministries, communities, local authorities, professional and scientific institutions could be strengthened both in policies and practices of risk reduction in rehabilitation and reconstruction process. 


\section{Acknowledgments}

The first author deeply appreciates and expresses gratitude to the National Development Planning Agency (Bappenas) for giving opportunities and precious life experiences in pursuing a master's degree in Urban and Regional Planning at Institut Teknologi Bandung, Indonesia and the Graduate School of Science and Engineering, Ritsumeikan University, Japan.

\section{References}

AHA Centre. (2018). SITUATION UPDATE NO. 10 M 7.4 EARTHQUAKE \& TSUNAMI Sulawesi, Indonesia. Ahlqvist, O. (2019). 'Overlay (in GIS).' In International Encyclopedia of Human Geography.

Bappeda Kota Palu. (2019). Rencana Aksi Daerah Rehabilitasi dan Rekonstruksi Pascabencana Gempabumi, Tsunami dan Likuifaksi Tahun 2019-2020 Kota Palu.

BNPB. (2015). Kerangka Kerja Sendai untuk Pengurangan Risiko Bencana 2015 - 2030.

BNPB. (2018). Rancangan Rencana Induk Penanggulangan Bencana (RIPB) tahun 2015-2045.

Boone, H. N., Boone, D. A., \& Virginia, W. (2012). Analyzing Likert Data Likert-Type Versus Likert Scales. 50(2).

Carter, W. N. (2008). Disaster Management: A Disaster Manager's Handbook. Manila: Asian Development Bank.

Center for Excellence in Disaster Management \& Humanitarian Assistance. (2018). Indonesia Disaster Management Reference Handbook.

Clinton, W. J. (2006). Lessons learned from tsunami recovery: key propositions for building back better. New York: Office of the UN Secretary-General's Special Envoy for Tsunami Recovery.

ESRI. (2013). The Language of Spatial Analysis. California: ESRI Press.

European Commission. (2018). Mw 7.5 Earthquake in Indonesia, 28 September 2018.

GFDRR. (2010). Building Back Better in Post-Disaster Recovery.

GFDRR. (2018). Building Back Better, Achieving Resilience Through Stronger, Faster, and More Inclusive Post-Disaster Reconstruction. Washington, DC.

Harpe, S. E. (2015). How to analyze Likert and other rating scale data. Currents in Pharmacy Teaching and Learning, 7(6), 836-850. https://doi.org/10.1016/j.cptl.2015.08.001

Kennedy, J., Ashmore, J., Babister, E., \& Kelman, I. (2008). The Meaning of 'Build Back Better': Evidence From Post-Tsunami Aceh and Sri Lanka. Journal of Contingencies and Crisis Management, 16(1).

Mannakkara, S. (2014). A Framework for Building Back Better During Post-Disaster Reconstruction and Recovery. The University of Auckland.

Mannakkara, S., \& Wilkinson, S. (2013a). 'Build back better' principles for land-use planning. Urban Design and Planning. ICE Virtual Library.

Mannakkara, S., \& Wilkinson, S. (2013b). Build Back Better principles for post-disaster structural improvements. Structural Survey, 31(4).

Mannakkara, S., \& Wilkinson, S. (2014). 'Re-conceptualising "Building Back Better" to improve postdisaster recovery.' International Journal of Managing Projects in Business, 7(3).

Ministry of Public Works and Housing. (2015). (RISHA) Rumah Instan Sederhana Sehat. Bandung: Ministry of Public Works and Housing.

Neuman, W. L. (2014). Social Research Method: Qualitative and Quantitative Approaches (Seventh). Edinburgh: Pearson Education Limited.

Paulik, R., \& Gusman, A. R. (2019). Tsunami Hazard and Built Environment Damage Observations from Palu City after the September 282018 Sulawesi Earthquake and Tsunami. Pure and Applied Geophysics, 176(3).

United Nations. (2016). Report of the open-ended intergovernmental expert working group on indicators and terminology relating to disaster risk reduction. 